\title{
Soft Drinks Consumer Segmentation Using Benefit Sought Variables-Case Study Kosovo Market
}

\author{
Arsim Begunca ${ }^{1}$
}

\begin{abstract}
Soft drinks market is a very large and important market where competition is very fierce. In recent years this market in global terms has not greatly increased. Thus for all the actors of this market without understanding (recognition) of the customer/consumer, they may lose a market share from competitors given the fierce competition. The purpose of this study is the identification of market segments within the city of Prishtina regarding soft drinks consumers based on requiredbenefits /benefits sought.

The result of this study supports the effectiveness of soft drinks consumer segmentation using the required benefit variables. Statistical Package for Social Science program ( SPSS version 20 ) was used for data analysis. This study used a descriptive analysis, factor analysis and cluster analysis. Based on differentiating factors in selecting soft drinks (refreshments), social-demographic variables and soft drinks consumer behavior throughout theses segments, the managers can modify their marketing strategies to fulfil the needs of these segments and at the same time maximize the profit.
\end{abstract}

Key words: benefit sought, soft drinks

\section{Introduction}

The segmentation based on sought benefits is an approach with which it is possible to identify market segments through more causal factors than descriptive factors. The basic belief of this strategy is that the benefits that people are looking at the consuming of any product are the fundamental reason for the existence of real segments and are better determinants of behavior than other approaches (Haley , 1968). Benefits better predict behavior rather than personality and lifestyle variables, demographic and geographic measurements, that simply describe the behavior without explaining them ( Haley, 1985; Young, Ott and Feagin ,1980).

Segmentation based on benefit sought is the consumer segmentation based on what special benefit from the product is attracting them. Different consumers require different benefits and marketers need to understand every segment and based on that develop their communication for each group.

According to Haley (1968) benefits that people look for in a particular product are the basic reasons for the existence of real market segmentation .Benefit sought segmentation is a technique that segments consumers based on benefit sought or required desires. These benefits when they are present as the attribute of the product, service or market supply, make consumers buy these products -rather than the simple description of who are the consumers in social-economic, demographic or psychographic terms. The benefit sought segmentation offers more benefits than traditional methods because it explains 
the reason why customers choose to buy a particular product or to hold to a particular supplier or a provider of services.

Important matter in this study is soft drink consumer segmentation based on required benefits (benefit sought).

\subsection{Problem definition and formulation}

Soft drinks market is a very large and important market where competition is very fierce. In recent years this market in global terms has not greatly increased. Thus for all the actors of this market without understanding (recognition) of the consumer, they may lose a market share from competitors given the fierce competition. The purpose of this study is the identification of market segments within the Kosovo market regarding soft drinks consumers based on benefits sought.

\subsection{The purpose of the study}

The main purpose of this study is the soft drink consumer segmentation in Kosovo based on benefits sought.

Other study objectives are:

1. To Identify differences between the behavior of consumers in the market segmentation based on benefits sought/required.

2. To identify behavior features/ characteristics based on benefit sought approach.

3. To identify personal features based on benefit sought.

4. Providing a guide for the development of effective segmentation strategies.

\subsection{Research hypothesis}

The main hypothesis of study is: there are significant differences between the behavior of consumers in different market segments based on benefits.

Subsidiary hypothesis are

Sub-hypothesis 1:there is a significant relationship between consumer demographic characteristics and benefit sought during the purchase of soft drinks.

Sub-hypothesis 2: there is a significant relationship between the characteristics of consumer behavior (consumption and loyalty) and benefit sought during purchase.

\section{Research methodology}

\subsection{Research method}

This study intends to segment soft drinks consumers based on benefits sought testing proposed hypothesis based on current theories. Quantitative approach is used more in this study than the qualitative approach. Quantitative approach is more suitable to test and evaluate the assumptions/hypothesis and to follow standard procedures which are strict in the used instruments and allow the statistical data analysis to identify relevant information related to soft drinks consumer in Kosovo.

The face to face survey with self-administered questionnaire was adopted in this study as a data collecting method. Alreck and Settle (1995) pointed out that self-administered questionnaires are an excellent way to ask responders and provide information, provided by an expert and when the appropriate instrument has been used. 


\subsection{Data collection}

Primary data on this topic are provided through various survey respondents in 20 cities in Kosovo. Through a self administered questionnaire we have surveyed a total of 400 responders, where the information obtained from these surveys is used as primary data and presents the essence of research.

The questionnaire consists of 27 questions; the series of questions are designed to have a range of responses focusing on the same general topic.

\subsection{Sample selection}

A self-administered questionnaire is used in this study that is directly distributed by the researcher in randomly selected sample. The study uses one scale sampling method. Therefore, Kosovo residents of ages 18 and up have been randomly selected in conducting this study.

\subsection{Methods of analysis}

Program called Statistical Package for Social Science (SPSS version 20) is used for data analysis. This study used factorial analysis, independent samples, Chi square test, one way between groups ANOVA and K-means cluster analysis

\section{Data analysis}

\subsection{Factor Analysis}

Factor analysis is applied in this study to reduce the number of variables, in order to make the study interpreted easier.

Before applying the PCA - Principal Components Analysis data adequacy of factor analysis is assessed or reviewed. Any issues in correlation matrix having a coefficient of less than 0.3 in any other matter were removed. Also the commonalities table is examined and any issue with less than 0.50 was also removed as a low value of commonalities, since they show that these variables don't have any relation to other variables in the community.(Field,2005; Tabachnick \& Fidell,2000).Factor analysis was performed using the Principal Component Analysis - PCA with orthogonal rotation(varimax). Orthogonal rotation was chosen because the resulting factors will be used in subsequent statistical analysis and this approach minimizes collinearity (Hair,Anderson,Totham \& Black,1998). Two sources of information were examined in order to determine the number of factors that will be elected, Eigenvalue size and Eigenvalue screeplot. Only factors with an Eigenvalue of 1 or more are taken into account and Screeplot diagram is checked for the information on the number of factors. 15 sought benefit issues were used through the factor analysis to fing essential dimensions of these issues. 15 sought benefits issues resulted with 6 factors having Eigenvalue more than 1.0, counting $76.494 \%$ of general variance in benefits. Benefits sought are consisted of six factors: consuming, health, sports-entertainment, economy, freshness and status of symbol factor. 
Table 1.1 Issues in the questionnaire regarding the benefits required from soft drinks

\begin{tabular}{|l|l|l|l|l|l|}
\hline \multicolumn{1}{|c|}{$\begin{array}{c}\text { Benefits from soft } \\
\text { drinks }\end{array}$} & $\begin{array}{c}\text { I do not agree } \\
\text { at all } 1\end{array}$ & $\begin{array}{c}\text { I do not agree } \\
2\end{array}$ & $\begin{array}{c}\text { Neutral } \\
3\end{array}$ & $\begin{array}{c}\text { I agree } \\
4\end{array}$ & $\begin{array}{l}\text { Fully agree } \\
5\end{array}$ \\
\hline Taste & 1 & 2 & 3 & 4 & 5 \\
\hline Low in calories & 1 & 2 & 3 & 4 & 5 \\
\hline Low price & 1 & 2 & 3 & 4 & 5 \\
\hline Popular brands & 1 & 2 & 3 & 4 & 5 \\
\hline Energy & 1 & 2 & 3 & 4 & 5 \\
\hline Quality & 1 & 2 & 3 & 4 & 5 \\
\hline Being natural & 1 & 2 & 3 & 4 & 5 \\
\hline Quenching thirst & 1 & 2 & 3 & 4 & 5 \\
\hline Image of the drink & 1 & 2 & 3 & 4 & 5 \\
\hline To be gassed & 1 & 2 & 3 & 4 & 5 \\
\hline Package/wrapping & 1 & 2 & 3 & 4 & 5 \\
\hline Freshness & 1 & 2 & 3 & 4 & 5 \\
\hline Entretainment & 1 & 2 & 3 & 4 & 5 \\
\hline Vitamins & 1 & 2 & 3 & 4 & 5 \\
\hline Caffeine & 1 & 2 & 3 & 4 & 5 \\
\hline
\end{tabular}

Table 1.2 Factor analysis results

\begin{tabular}{lll}
\hline Factor & Eigen values & Variance $(\%)$ \\
\hline Consumption factor & 3.101 & 19.381 \\
Sport-entretainment factor & 2.807 & 17.540 \\
Health factor & 1.733 & 10.831 \\
Economy factor & 1.683 & 10.518 \\
Freshness factor & 1.542 & 9.637 \\
Symbol status factor & 1.374 & 8.587 \\
Total & & 76.494 \\
\hline
\end{tabular}

\subsection{Cluster Analysis}

Cluster analysis is one of statistical analysis that is used in many segmentation studies in defining groups. There are two main subdivisions of clustering procedures, when the number of clusters is default/determined then K-means Cluster method is used and hierarchy cluster analysis is used when the number of clusters is not predetermined. K - Means cluster analysis is used to identify relatively homogeneous groups of cases based on selected characteristics for this study. $\mathrm{K}$ - Means cluster analysis procedure requires that cluster number should be specified in order to continue with the analysis. K-Means attempts to to identify relatively homogeneous groups of cases based on selected characteristics using an algorithm that can manipulate large numbers of cases 
Table 1.3 Cluster analysis results

\begin{tabular}{|c|c|c|c|c|c|c|c|}
\hline Market & $\begin{array}{l}\text { No. } \\
\text { of }\end{array}$ & & & Results in each se & & & \\
\hline & & $\begin{array}{l}\text { Consum } \\
\mathrm{e}\end{array}$ & Health & $\begin{array}{l}\text { Entertainment.- } \\
\text { sports. }\end{array}$ & $\begin{array}{l}\text { Econom } \\
\mathrm{y}\end{array}$ & $\begin{array}{l}\text { Freshnes } \\
\mathrm{s}\end{array}$ & $\begin{array}{l}\text { Symbol } \\
\text { status }\end{array}$ \\
\hline $\begin{array}{l}\text { Segment } \\
1 \\
\text { Segment }\end{array}$ & 53 & 0.41 & -0.59 & 0.27 & 0.15 & 0.19 & -0.57 \\
\hline $\begin{array}{l}2 \\
\text { segment }\end{array}$ & 43 & 0.23 & 0.19 & 0.42 & 0.11 & 0.27 & 0.13 \\
\hline & 37 & 0.12 & 0.45 & 12 & -0.37 & 0.22 & 0.17 \\
\hline $\begin{array}{l}4 \\
\text { Segment }\end{array}$ & 35 & 0.32 & 0.26 & 16 & -1.54 & 0.47 & 0.24 \\
\hline 5 & 32 & 0.35 & 0.12 & -0.47 & -1.37 & 0.28 & 0.47 \\
\hline
\end{tabular}

Five cluster selections are validated using ANOVA, resulting in significant differences through 5 clusters in all benefit factors. These results support the concept that there are benefit based segments that can be drawn throughout customers/consumers.

Segments are described as follows:

Segment 1: represents $26.5 \%$ of the sample (responders). This segment includes responders who give more importance/attention to consumption factor (taste and thirst quenching), followed by sports and entertainment factor (entertainment, energy). Also the aspect of freshnes that these drinks offer is important.

Segment 2: represent $21.5 \%$ of the sample. This segment includes responders who give more importance/attention to entertainment and sports factor, followed by freshness and consumption.

Segment 3: represents $18.5 \%$ of the sample. This segment includes responders who give more importance/attention to health aspects (low calories, to be natural, vitamins) followed by freshness and symbol status (image, quality, famous brands).

Segment 4: represents $17.5 \%$ of the sample. This segment includes responders who give more importance/attention to freshness aspects (to be gassed, freshness, caffeine), followed by consumption factor and symbol status factor.

Segment 5 : represents $16 \%$ of the sample. This segment includes responders who give more importance/attention to status of symbol (image, quality, famous brands), followed by consumption and freshness factor.

\subsection{Testing hypothesis}

In order to verify the research hypothesis we have used ANOVA and CHI SQUARE tests, and we achieved the following results that are reflected on the table . 
Table 1.4 Result of hypothesis testing

\begin{tabular}{|c|c|c|c|c|c|}
\hline Variables & Type of test & $\begin{array}{l}\text { The test } \\
\text { Static }\end{array}$ & $\begin{array}{l}\text { Degrees of } \\
\text { freedom }\end{array}$ & $\begin{array}{l}\text { significant } \\
\text { level }\end{array}$ & $\begin{array}{l}\text { test } \\
\text { results }\end{array}$ \\
\hline Age & Anova & 0.51 & 1 & 0.173 & rejected \\
\hline $\begin{array}{l}\text { Gender } \\
\text { Marital }\end{array}$ & Chi square & 9.54 & 1 & 0.006 & confirmed \\
\hline Status & Chi square & 10.43 & 4 & 0.009 & confirmed \\
\hline Family & Anova & 4.71 & 4 & 0.007 & confirmed \\
\hline \multicolumn{6}{|l|}{ Members } \\
\hline Occupation & Chi square & 1.13 & 3 & 0.001 & confirmed \\
\hline Education & Chi square & 65.36 & 5 & 0.000 & confirmed \\
\hline Income & Chi square & 58.74 & 4 & 0.000 & confirmed \\
\hline Consumption & Chi square & 22.37 & 4 & 0.000 & confirmed \\
\hline Loyalty & Anova & 3.72 & 4 & 0.004 & confirmed \\
\hline
\end{tabular}

From data given on the table we come to conclude that:

Hypothesis H1: There is a significant relationship between consumer demographic characteristics and benefits sought when purchasing soft/refreshment drinks- partially confirmed.

Hypothesis H2: There is a significant relationship between consumer behavior characteristics/ features (consumption and loyalty) and benefits sought during purchasecompletely confirmed.

\section{Conclusions, Implications of the study, study limitations and suggestions for future studies.}

\subsection{Conclusions}

Through a series of analysis we have achieved through cluster analysis to group customers into five benefit sought/required segments. By putting consumers in 5 benefits sought segmentized groups we have provided answers to our main goal which has been soft drinks customer segmentation based on benefits sought variables. With these practical results of the study we have concluded that soft drinks consumers can be segmented according to benefits sought/required by supporting the conclusion of the existing theory that every industry needs its own instruments to conduct researches for effective market segmentation.

\subsection{Study implications}

Results from this study can help the soft drinks industry in establishing marketing strategies by providing a clear picture of segmented groups. Having submitted our main goal that was segmentation of soft drinks consumers based on benefits sought/required, we provide a good analytical base for soft drink market segmentation, better positioning of the product on market and more effective advertising. 


\subsection{Study limitations}

Main limitations can be summarized in two issues; responders number or sample's size and study instrument construction. In order to accomplish the study we surveyed 400 responders soft drinks consumers. Therefore small number of responders represents the main limitation/constraint of the study and its applicability since it can not represent the entire population of Kosovo broadly, despite efforts for a right inclusion. Another constraint of the study relates to the construction of the survey instrument, where the scales used are not uniform. These varying scales/degrees are used because of the different references used for study questions in questionnaire.

\subsection{Suggestions for future studies.}

Future research in this area should include various issues that are not included in this study. It is suggested that study instrument should include more issues/cases, this is because the more cases/issues are to be addressed and the more responders are to be interviewed the results are more accurate and their application in practice is easier and more effective, also responders number should not be under 1000 .

Also it is suggested to carry out a thorough beverage market research in Kosova by using different variables including the benefit sought variables.

\section{References}

Kotler P (1997). Marketing Management: Analysis, Planning, Implementation, and Control. Prentice-Hall. Englewood Cliffs.NJ.

Kotler P (1999). Marketing Management: The Millennium. Prentice-Hall. Englewood Cliffs. NJ.

Kotler P (2002). Principles of Marketing. Prentice-Hall Europe. London.

Kuma N, Cheer L, Kotler P (2000), From market-driven to market-driving. European Management. J. 18 )2( :129-41).

Russell I, Haley (1968). Benefit Segmentation: A Decision-Oriented Research Tool. J. Mark. 32)3 (: 30-35

Calantone, J. and A.G. Sawyer (1978) “The Stability of Benefit Segments,"Journal of Marketing Research, Vol. 15, pp.395-404

Cermak, Dianne S.P., Karen Maru File and Russ Alan Prince (1994) "A Benefit Segmentation of the Major Donor Market," Journal of Business Research,Vol. 29, pp.121-130.

Cholewka, Kathleen (2001) "Standing out online: The 5 best e-marketing campaigns," Sales and Marketing Management,Vol. 153, No. 1, pp.51-57.

Chang, Tung-Zong and Su-Jane Chen (1995) "Benefit segmentation: Auseful tool for financial investment services," Journal of Professional Services Marketing, Vol. 12, No. 2, pp.69-77.

Culnan, Mary J. (1999) Georgetown Internet Privacy Policy Survey: Repor to the Federal Trade Commission (June), http://www.msb.edu/faculty/culnanm/gippshome/html, accessed July 27, 1999.

Dubow (1992) "Occasion-Based vs. User-Based Benefit Segmentation:Acase study," Journal of Advertising Research, pp.11-18.

Myers, J.H. (1976) "Benefit Structure Analysis:ANew Tool for Product Planning," Journal of Marketing, Vol. 40, pp.23-32.

Cohen,J.(1988).Statistical Power Analysis for the Behavioral Sciences(2nd edition).Hisdalle,N.J.: Lawrence Erlbaum Associates

Field,A.P.(2005).Discovering Statistics Using SPSS(2nd edition),London:Sage.

Pallant,J(2001).SPSS Survival Manual:A Step by Step Guide to Data Analysis using SPSS for Windows9version 10).Crow Nest,N.S.W.,:Allen and Unwin. 